\title{
Diagnosis of disruptive mood dysregulation disorder in offsprings of bipolar parents
}

\author{
Youmna Sabri*
}

\begin{abstract}
Background: Disruptive mood dysregulation disorder (DMDD) was introduced in (DSM-5) as a new diagnostic category to get control on the exaggerated diagnosis of bipolar disorder in children and adolescents which was elevated more than 40 times in the last decade. Few studies were done recently to explore the role of family history of bipolar disorder in the occurrence of DMDD in children and adolescents. Unfortunately, there is limited number of studies about the familial transmission of DMDD.

The aim of this study is to examine the presence of a relation between DMDD and the presence of a family history of bipolar disorder through comparing the diagnosis of DMDD in offspring of parents with (a) bipolar disorder and (b) a control group.
\end{abstract}

Results: The distribution of psychiatric disorders among the studied groups highlighted that DMDD and depressive disorder are significantly present in the offsprings of bipolar parents more than in the offsprings of control parents. DMDD is significantly present among offsprings of bipolar parents aged $\leq 11$ years old $\left(p=0.008^{*}\right)$. Also, DMDD is significantly $(p=0.02)$ present among male offsprings of bipolar parents. Also, depressive disorder is significantly ( $p=$ 0.002 ) present among female offsprings of control parents. While significant comorbidity between DMDD and depressive disorders $\left(p=0.018^{*}\right)$ was detected.

Conclusions: This study revealed that DMDD and depressive disorders are significantly present in the offsprings of bipolar parents higher than in the offsprings of control parents. DMDD is significantly present among the offsprings of bipolar parents aged $\leq 11$ years old.

The relation between sex and affective disorders among the offsprings was also assessed revealing that DMDD is significantly present among male offsprings of bipolar parents. Also, depressive disorders are significantly present among female offsprings of control parents.

Potential implications

This study has several clinical implications. This study draws attention to the importance of the careful assessment of the offsprings of bipolar patients to check the presence of different childhood psychiatric disorders such as DMDD. Also, symptoms of temper outbursts and persistent irritability in childhood require the necessary of psychiatric evaluation not only for the patients but also for their families. In addition, this study highlights the need for accurate updated diagnostic instruments to differentiate between these overlapping symptoms.

As regards implications for future research, following-up of children diagnosed with DMDD to recognize the prognostic outcome of this new diagnostic category is necessary.

Keywords: Disruptive mood dysregulation disorder, Offsprings, Bipolar parents

*Correspondence: youmnasabri@yahoo.com

Psychiatry, Department of Psychiatry, Faculty of Medicine, Mansoura

University, Mansoura, Egypt 


\section{Background}

Disruptive mood dysregulation disorder (DMDD) was introduced in (DSM-5) as a new diagnostic category to get control on the exaggerated diagnosis of bipolar disorder in childhood [1]. Researchers reported that pediatric bipolar disorder (PBD) and bipolar disorder (BD) in adults vary in the clinical picture as PBD is presented by persistent irritability more than the classic manic symptoms resulting in increase in the diagnosis of PBD [2].

The DMDD diagnosis requires two main criteria: severe recurrent temper outbursts and chronic non-episodic irritability with childhood onset [3].

Currently, there is limited number of studies on DMDD regarding it is a new diagnosis. In addition, the estimated prevalence of DMDD is uncertain as most of the reported results are based on diagnostic interviews not designed specifically to assess DMDD [4].

A recent study [5] estimated the prevalence of DMDD (4.4\%), and another one reported a range from 0.12 to $3.3 \%$ [6]. Also, in another study, DMDD was more detected in young aged males [7].

Copeland et al. [8] found that $45-50 \%$ of school-age children had severe temper outbursts, which decreased to $8 \%$ with the application of the DSM- 5 frequency criterion, and it decreased more to $3 \%$ with the duration criterion. When applying all DSM-5 diagnostic criteria, the percentage decreased to about only $1 \%$.

Few recent studies have demonstrated co morbidity of DMDD with other childhood psychiatric disorder; recent study [9] reported that children with DMDD had significant co morbidity of ODD and depression. Results of another study [10] reported higher comorbidity of ADHD and ODD in children who had DMDD than a control group.

Another recent research reported [11] that DMDD was more detected in children of parents with bipolar disorder than in those of control parents (ratio $8 \%$ vs. $0.8 \%$ ).

A study tried to explore the pathophysiology of DMDD demonstrated abnormal activation of neural pattern in dorsal anterior cingulated cortex, anterior insula, and amygdale [12].

Also, hypersensitivity can magnify stimulus-responses, leading to patterned thinking, consequently leading to increasing goal blockage, anger, and frustration [13].

Another recent study reported impaired brain activation in reward processing areas associated with in children with symptoms of DMDD [14].

A recent research [15] about the pathophysiology of both DMDD and bipolar disorder in children reported that the children of DMDD group showed irritability in response to for all emotions (happy, fearful, and angry faces) while children with bipolar disorder showed irritability only for fearful faces.
Few studies were done recently to explore the role of family history of bipolar disorder in the occurrence of DMDD in children and adolescents [16]. Unfortunately, there are limited number of studies about the familial transmission of DMDD [17].

Theoretically, if the path physiology of DMDD overlap with that of bipolar disorder; DMDD is supposed to be more diagnosed in the children of bipolar parents.

Perhaps, research in this point can reveal an answer about the nature of the relationship between DMDD and bipolar disorder.

The aim of this study is to examine the presence of a relation between DMDD and the presence of a family history of bipolar disorder through comparing the diagnosis of DMDD in offspring of parents with (a) bipolar disorder and (b) a control group.

\section{Methods}

This study was conducted at the Psychiatry Department, Faculty of medicine, Mansoura University Hospitals (MUH) during the period From February 2021 to September 2021.

Forty-eight bipolar patients and 49 control with no mood disorder and their offspring's were asked to participate in this study; 8 patients and 4 control refused to participate (not interested, personal causes).

Finally, 85 biological parents joined this study; $40(n=$ 40) bipolar patients group and $45(n=45)$ control group.

All participating parents signed written informed consent and were informed that all information obtained will be confidential.

Sample size calculation was based on the result of internal pilot study that is carried out on 35 cases and revealed that prevalence of distributive mood disorders among cases with bipolar mood disorders them is $2.8 \%$. Using Epi info version 7.2.4.0 to calculate sample size based on $2.8 \%, 95 \%$ CI with acceptable margin of error $=5$ then the total sample size will be 40 cases. Cases included in the pilot study were excluded from analysis.

\section{Parents' assessments}

The Mood Disorder Questionnaire [18] was administered to all parents who joined this study is a short self-report screening instrument; Arabic version was prepared through translation and back translation. The first part includes 13 items, symptoms of manic or hypomanic episode. The next part detects if many of the symptoms occurred in the same time (seven or more symptoms are needed), and the last evaluates the problem consequences of these symptoms.

\section{a) The bipolar parents group}


- From both sex.

- Being biological parent of children aging (6-18 years old).

- Diagnosed as bipolar patients: according to the Mood Disorder Questionnaire, clinical diagnosis of this group according to DSM-V criteria was done by at least two senior staff through psychiatric history taken from the patients, their relatives, available medical records, and follow-up.

\section{b) The control parents group}

- From both sex

- being biological parent of children aging (6-18 years old)

- Should not be bipolar patients: according to the Mood Disorder Questionnaire.

- Control parents with other psychiatric disorders were excluded.

\section{Offsprings assessments \\ Inclusion criteria}

- Having at least one biological parent (either group (a) or group (b)).

- Aged (6-18 years); age of diagnosis of DMDD.

\section{Exclusion criteria}

- Brain injuries

- Or intellectual disability which may interfere with assessment.

All children and adolescents who joined this study were assessed by the depressive and bipolar-related disorders supplement of K-SADS-PL DSM-5 [19] which is a semistructured diagnostic interview for detection of depressive and bipolar-related disorders.

The new module of DMDD in this supplement evaluates symptoms of DMDD; frequency (three or more times/week), severe temper outbursts out of proportion to the developmental level, persistent irritability with onset before age of 10 years. Symptoms are rated as 1, absent; 2, present at sub threshold level; or 3, present at threshold level.

This study used a modified translation of the depressive and bipolar-related disorders supplement of the Arabic version of K-SADS-PL DSM-IV (Moussa et al. 2011) [20]. The author re-edited all the changes that took place in (K-SADS-PL DSM-5). The translation was revised by Prof. S. Moussa.
Table 1 Sociodemographic data of parents of the studied groups

\begin{tabular}{|c|c|c|c|c|c|}
\hline & $\begin{array}{l}\text { Bipolar pare } \\
(n=40)\end{array}$ & & $\begin{array}{l}\text { Control pare } \\
(n=45)\end{array}$ & & $\begin{array}{l}\text { Test of } \\
\text { significance }\end{array}$ \\
\hline \multicolumn{6}{|l|}{ Age/years } \\
\hline Mean \pm SD & $48.29 \pm 2.92$ & & $47.94 \pm 2.81$ & & $\begin{array}{l}t=0.563 \\
P=0.575\end{array}$ \\
\hline \multicolumn{6}{|l|}{ Sex } \\
\hline Male & 15 & 37.5 & 20 & 44.4 & $x^{2}=0.422$ \\
\hline Female & 25 & 62.5 & 25 & 55.6 & $P=0.516$ \\
\hline \multicolumn{6}{|l|}{ Residence } \\
\hline Urban & 40 & 100 & 45 & 100 & $P=1.0$ \\
\hline
\end{tabular}

$t$ Student's $t$ test, $X^{2}$ chi-square test

Table 2 Sociodemographic data of the offsprings

\begin{tabular}{clll}
\hline & $\begin{array}{l}\text { Offsprings } \\
\text { of bipolar } \\
\text { parents } \\
\boldsymbol{n}=\mathbf{6 8}\end{array}$ & $\begin{array}{l}\text { Offsprings } \\
\text { of control } \\
\text { parents } \\
\boldsymbol{n}=\mathbf{6 8}\end{array}$ & Test of significance \\
\hline Age/years & & & \\
Mean \pm SD & $11.69 \pm 2.77$ & $11.46 \pm 2.55$ & $t=0.515$ \\
min-max & $(7.0-18.0)$ & $(8.0-18.0)$ & $p=0.607$ \\
Sex & $16(23.5)$ & $38(55.9)$ & $X^{2}=6.44$ \\
Female & $52(76.5)$ & $30(44.1)$ & $p=0.01^{*}$ \\
Male & & &
\end{tabular}

$t$ Student's $t$ test, $x^{2}$ chi-square test

*Statistically significant if $p<0.05$

\section{Results}

Table 1 demonstrated sociodemographic data of parents in the examined groups; in concern to bipolar parents $(n=40)$ mean of age \pm SD was $48.29 \pm 2.92$, 15(37.5\%) males, 25(62.5\%) females, and 40(100\%) urban. While in control parents $(n=45)$, mean of age $\pm \mathrm{SD}$ was $47.94 \pm 2.81$. 20(44.4\%) males, $25(55.6 \%)$ females, and 45 (100\%) urban.

Table 2 demonstrated socio demographic data of the offspring of the studied groups; in concern to offspring of bipolar parents $(n=68)$ mean of age \pm was $11.69 \pm$ 2.77, $52(76.5 \%)$ male, $16(23.5 \%)$ female with significant difference $\left(p=0.01^{*}\right)$. While in offspring of control parents $(n=68)$, mean of age \pm SD was $11.46 \pm$ 2.55. 30 (44.1\%) male, and 38 (55.9\%) female.

Table 3 highlighted the distribution of psychiatric disorders among the studied groups; DMDD ( $p<$ $0.001)$, depressive disorder $(p=0.025)$ are significantly present in the offsprings of bipolar parents than in the offsprings of control parents.

These results have been also clarified in Fig. 1. 
Table 3 Affective disorders among the offsprings groups

\begin{tabular}{llll}
\hline & $\begin{array}{l}\text { Offsprings of } \\
\text { bipolar parents } \\
\boldsymbol{n}=\mathbf{6 8}(\%)\end{array}$ & $\begin{array}{l}\text { Offsprings of } \\
\text { control parents } \\
\boldsymbol{n}=\mathbf{6 8}(\%)\end{array}$ & Test of significance \\
\hline DMDD & $34(50.0)$ & $14(20.6)$ & $x^{2}=12.88, p<0.001^{*}$ \\
$\begin{array}{l}\text { Depressive } \\
\text { disorders }\end{array}$ & $21(30.9)$ & $10(14.7)$ & $x^{2}=5.06, p=0.025^{*}$ \\
Mania & $5(7.4)$ & $2(2.9)$ & $x^{2}=1.35, p=0.244$ \\
\hline
\end{tabular}

$x^{2}$ chi-square test

*Statistically significant if $p<0.05$

Figure 1 highlighted the distribution of affective disorders among the offsprings groups; DMDD, depressive disorders are significantly present in the offsprings of bipolar parents than in the offsprings of control parents

Table 4 showed the relation between age and psychiatric disorders among studied groups; DMDD is significantly present among the offsprings of bipolar parents aged $\leq 11$ years old $\left(p=0.008^{*}\right)$.

Table 5 showed the relation between sex and affective disorders among the offsprings; $D M D D$ is significantly $(p=0.02)$ present among male off springs of bipolar parents. Also, depressive disorder is significantly ( $p$ $=0.002$ ) present among female offsprings of control parents

\section{Statistical analysis and data interpretation}

Data were introduced and analyzed using IBM SPSS Corp. Released 2013. IBM SPSS Statistics for Windows, Version 22.0. Armonk, NY: IBM Corp. Qualitative data were expressed by number and percent. Quantitative data were expressed by mean, standard deviation for parametric data after testing normality using Kolmogrov-Smirnov test. Significance was judged at the 0.05 level.

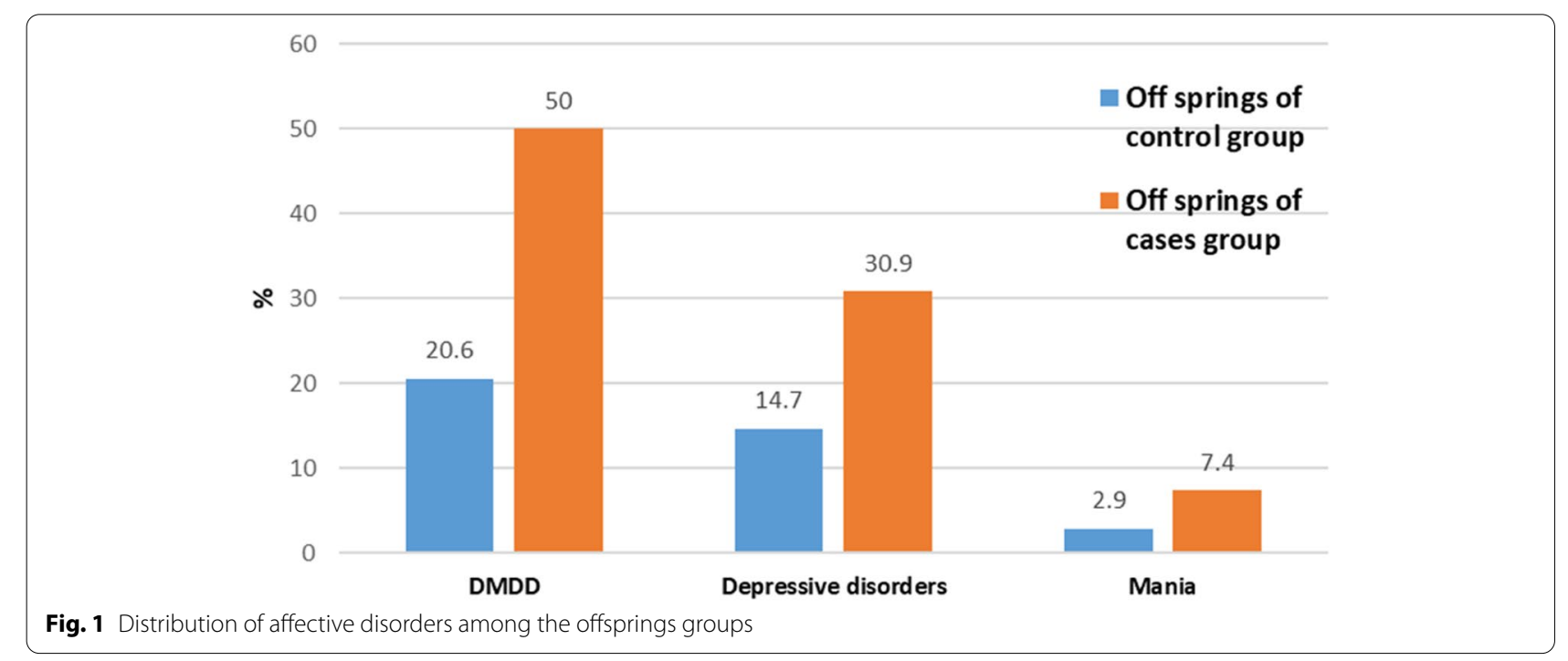

Table 4 Relation between age and affective disorders among the offsprings

\begin{tabular}{|c|c|c|c|c|c|c|}
\hline \multirow[t]{2}{*}{ Affective disorders } & \multicolumn{2}{|c|}{$\begin{array}{l}\text { Age/years } \\
\text { among offsprings of bipolar } \\
\text { parents }\end{array}$} & \multirow[t]{2}{*}{ Test of significance } & \multicolumn{2}{|c|}{$\begin{array}{l}\text { Age/years } \\
\text { among offsprings of control } \\
\text { parents }\end{array}$} & \multirow[t]{2}{*}{ Test of significance } \\
\hline & $\begin{array}{l}\leq 11 \\
n=33\end{array}$ & $\begin{array}{l}>11 \\
n=35\end{array}$ & & $\begin{array}{l}\leq 11 \\
n=38\end{array}$ & $\begin{array}{l}>11 \\
n=30\end{array}$ & \\
\hline DMDD & $22(66.7)$ & $12(34.3)$ & $x^{2}=7.12, p=0.008^{*}$ & $7(18.4)$ & $7(23.3)$ & $\begin{array}{l}x^{2}=0.247 \\
p=0.619\end{array}$ \\
\hline Depressive disorders & $10(30.3)$ & $11(31.4)$ & $x^{2}=0.01, p=0.920$ & $7(18.4)$ & $3(10.0)$ & $\begin{array}{l}x^{2}=0.948 \\
p=0.33\end{array}$ \\
\hline Mania & $2(5.7)$ & $3(9.1)$ & $\mathrm{FET}, p=0.668$ & 0 & $2(5.3)$ & $\begin{array}{l}\text { FET, } \\
p=0.500\end{array}$ \\
\hline
\end{tabular}

$x^{2}$ chi-square test, FET Fisher's exact test

*Statistically significant if $p<0.05$ 
Table 5 Relation between sex and affective disorders among the offsprings

\begin{tabular}{|c|c|c|c|c|c|c|}
\hline \multirow[t]{2}{*}{ Affective disorders } & \multicolumn{2}{|c|}{$\begin{array}{l}\text { Sex among offsprings of } \\
\text { bipolar parents }\end{array}$} & \multirow[t]{2}{*}{ Test of significance } & \multicolumn{2}{|c|}{$\begin{array}{l}\text { Sex among offsprings of } \\
\text { control parents }\end{array}$} & \multirow[t]{2}{*}{ Test of significance } \\
\hline & $\begin{array}{l}\text { Female } \\
n=16\end{array}$ & $\begin{array}{l}\text { Male } \\
n=52\end{array}$ & & $\begin{array}{l}\text { Female } \\
n=38\end{array}$ & $\begin{array}{l}\text { Male } \\
n=30\end{array}$ & \\
\hline DMDD & $4(25.0)$ & $30(57.7)$ & $x^{2}=5.23, p=0.02^{*}$ & $8(21.1)$ & $6(20.0)$ & $x^{2}=0.01, p=0.915$ \\
\hline Depressive disorders & $12(75.0)$ & $17(32.7)$ & $x^{2}=0.339, p=0.560$ & $10(26.3)$ & 0 & $x^{2}=9.26, p=0.002^{*}$ \\
\hline Mania & $3(18.8)$ & $2(3.8)$ & FET $p=0.046^{*}$ & $2(5.3)$ & 0 & FET $p=0.202$ \\
\hline
\end{tabular}

$X^{2}$ chi-square test, FET Fisher's exact test

*Statistically significant if $p<0.05$

\section{Data analysis}

\section{Qualitative data}

Chi-square test for comparison of 2 or more groups.

Fischer Exact test was used as correction for chi-square test when more than $25 \%$ of cells have count less than 5 in $2 \times 2$ tables.

\section{Quantitative data between groups}

Parametric tests

Student's $t$ test was used to compare 2 independent groups

\section{Discussion}

The aim of this study is to examine the presence of a relation between DMDD and the presence of a family history of bipolar disorder through comparing the diagnosis of DMDD in offspring of parents with (a) bipolar disorder and (b) a control group.

Results of this study revealed that DMDD and depressive disorders are significantly present among the offsprings of bipolar parents more than the offsprings of control parents.

This study tried to find an answer about the nature of the relationship between DMDD and bipolar disorder. The current results suggest the presence of a significant role of family history of bipolar disorder in the development of DMDD in the offsprings.

This finding may be explained by the overlapped pathophysiology of both DMDD and bipolar disorder in children. A recent research [15] about the pathophysiology of both DMDD and bipolar disorder in children reported that the children of DMDD group showed irritability in response to for all emotions (happy, fearful, and sad) while children with bipolar disorder showed irritability only for fearful faces.

Theoretically, if the pathophysiology of DMDD overlaps with that of bipolar disorder, DMDD is supposed to be more diagnosed in the children of bipolar parents.

Another recent research reported [12] that DMDD was more detected in children of parents with bipolar disorder than in those of control parents (ratio 8\% vs.
$0.8 \%$ ), while the results of another recent study disagree with these results denying the presence of a specific relation between diagnosis of DMDD and presence of family history of bipolar disorder [21].

Also, this study examined the relation between age and affective disorders among the studied groups reporting that DMDD is significantly present among the offsprings of bipolar parents aged $\leq 11$ years old. But this finding may be a result of the DSM-5 criteria for diagnosis of the DMDD [22]; age at onset is before 10 years and diagnosis should not be done before age 6 years or after 18 years.

The relation between sex and affective disorders among studied groups was also assessed revealing that DMDD is significantly present among males offsprings of bipolar parents. While depressive disorders are significantly present among female offsprings of control parents.

This finding may be due to cultural perspectives which allow the DSM-5 criterion for diagnosis of DMDD (severe recurrent temper outbursts out of proportion to the developmental level) to be expressed by boys not by girls.

Recent study [8] confirmed the previous data reporting that DMDD was more detected in young aged males [8].

Before conclusion, several limitations of this study should be mentioned; the first is that this study was done on offspring of parents with (a) bipolar disorder and (b) a control group while offspring of parents with other psychiatric disorders were not included.

Second, our sample size was limited and larger studied groups are needed to assure the current results.

Finally, the Arabic version of the all supplements of K-SADS-PL DSM-IV was prepared by a team of eight researchers (Moussa et al. 2011) [20].

The author of this research re-edited only the depressive and bipolar-related disorders supplement of K-SADS-PL DSM-5 which includes the new module of DMDD. The translation was revised by Prof. S. Moussa.

So, other psychiatric disorders in the K-SADS-PL DSM-5 that may be found in the offsprings should 
be translated and prepared to be used in the future researches.

\section{Conclusions}

This study revealed that DMDD, depressive disorders are significantly present in the offsprings of bipolar parents higher than in the offsprings of control parents. DMDD is significantly present among offsprings of bipolar parents aged $\leq 11$ years old .

The relation between sex and affective disorders among the offsprings was also assessed revealing that DMDD is significantly present among male offsprings of bipolar parents. Also, depressive disorders are significantly present among females offsprings of control parents.

\section{Potential implications}

This study has several clinical implications. As this study draws attention to the importance of the careful assessment of the offsprings of bipolar patients to check the presence of different childhood psychiatric disorders such as DMDD. Also, symptoms of temper outbursts and persistent irritability in childhood require the necessary of psychiatric evaluation not only for the patients but also for their families. In addition, this study highlights the need for accurate updated diagnostic instruments to differentiate between these overlapping symptoms. As regards implications for future research, following-up of children diagnosed with DMDD to recognize the prognostic outcome of this new diagnostic category is necessary.

\section{Abbreviations}

DMDD: Disruptive mood dysregulation disorder; PBD: Pediatric bipolar disorder; BD: Bipolar disorder; DSM-5: Diagnostic and Statistical Manual of Mental Disorders, Fifth Edition; ODD: Oppositional-defiant disorder; MUH: Mansoura University Hospitals; K-SADS-PL: the Schedule for Affective Disorders and Schizophrenia for School Aged Children for DSM-5, Present and Lifetime version.

\section{Acknowledgements}

The author is sincerely thanking and appreciating Prof. Dr. Soad Mousa for her support and guidance. Also, the author would like to appreciate all participants in this study.

\section{Author's contributions}

Y.S prepared the study design, conducted the psychiatric assessment, collected and interpreted the data, wrote and revised the manuscript. The author read and approved final manuscript.

\section{Funding}

No funds

\section{Availability of data and materials}

Data are available with the request from the corresponding author.

\section{Declarations}

Ethics approval and consent to participate

All subjects signed a written informed consent before starting the research. The study was approved by the Institutional Research Board-IRB Faculty of Medicine -Mansoura University, reference code is "R.21.06.1365.R1.R2".

\section{Consent for publication}

Not applicable.

\section{Competing interests}

The author declares no competing interests.

Received: 6 January 2022 Accepted: 20 February 2022

Published online: 07 March 2022

\section{References}

1. Carlson GA (2016) Disruptive mood dysregulation disorder: where did it come from and where is it going. J Child Adolesc Psychopharmacol 26:90-93

2. James A, Hoang U, Seagroatt V (2014) A comparison of American and English hospital discharge rates for pediatric bipolar disorder. J Am Acad Child Adolesc Psychiatry 53:614-624

3. Mayes SD, Waxmonsky JD, Waschbusch DA, Mattison RE, Baweja R (2016) Mother, Father, and Teacher Agreement on Disruptive Mood Dysregulation Disorder Symptoms in Children with Psychiatric Disorders. Int J Ment Health Psychiatry 2:2. https://doi.org/10.4172/2471-4372.1000123

4. Copeland WE, Angold A, Costello EJ, Egger H (2013) Prevalence, co morbidity , and correlates of DSM-5 proposed disruptive mood dysregulation disorder. Am J Psychiatry 170:173-179

5. Freeman AJ, Youngstrom EA, Youngstrom JK, Findling RL (2016) Disruptive mooddysregulation disorder in a community mental health clinic: prevalence, comorbidity and correlates. J Child Adolesc Psychopharmacol 26:123-130

6. Althoff RR, Crehan ET, He JP, Burstein M, Hudziak JJ, Merikangas KR (2016) Disruptive mood dysregulation disorder at ages 13-18: results from the National Comorbidity Survey - Adolescent Supplement. J Child Adolesc Psychopharmacol 26:107-113

7. Mitchell RH, Timmins V, Collins J, Scavone A, Iskric A, Goldstein BI (2016) Prevalence and correlates of disruptive mood dysregulation disorder among adolescents with bipolar disorder. J Child Adolesc Psychopharmacol 26:147-153

8. Copeland WE, Shanahan L, Egger H, Angold A, Costello EJ (2014) Adult diagnostic and functional outcomes of DSM-5 disruptive mood dysregulation disorder. Am J Psychiatry. 171(6):668-674

9. Dougherty LR, Smith VC, Bufferd SJ, Carlson GA, Stringaris A, Leibenluft E, Klein DN (2014) DSM-5 disruptive mood dysregulation disorder: Correlates and predictors in young children. Psychol Med 44:2339-2350

10. Mayes SD, Waxmonsky JD, Calhoun SL, Bixler EO (2016) Disruptive mood dysregulation disorder symptoms and association with oppositional defiant and other disorders in a general population child sample. J Child Adolesc Psychopharmacol 26(2):101-106

11. Sparks GM, Axelson DA, Yu H (2014) Disruptive mood dysregulation disorder and chronic irritability in youth at familial risk for bipolar disorder. J Am Acad Child Adolesc Psychiatry 53(4):408-416

12. Wiggins JL, Brotman MA, Adleman NE (2016) Neural correlates of irritability in disruptive mood dysregulation and bipolar disorders. Am J Psychiatry. 173(7):722-730

13. Kessel EK, Dougherty LR, Kujawa A, Hajcak G, Carlson GA, Klein DN (2016) Longitudinal associations between preschool disruptive mood dysregulation disorder symptoms and neural reactivity to monetary reward during preadolescence. J Child Adolesc Psychopharmacol 26(2):131-137

14. Deveney CM, Connolly BA, Haring BA (2013) Neural mechanisms of frustration in chronically irritable children. Am J Psychiatry 170(10):1186-1194

15. Rich BA, Carver FW, Holroyd T (2011) Different neural pathways to negative affect in youth with pediatric bipolar disorder and severe mood dysregulation. J Psychiatr Res 45(10):1283-1294 
16. Towbin K, Axelson D, Leibenluft E, Birmaher B (2016) Differentiating bipolar disorder-not otherwise specified and severe mood dysregulation. J Am Acad Child Adolesc Psychiatry 52(5):466-481

17. Fristad MA, Wolfson H, Algorta GP (2016) Disruptive mood dysregulation disorder and bipolar disorder not otherwise specified: fraternal or identical twins? J Child Adolesc Psychopharmacol 26(2):138-146

18. Hirschfeld RMA, Williams JBW, Spitzer RL, Calabrese JR, Flynn L, Keck PE Jr, Flynn L, Keck PE Jr, Lewis L, McElroy SL, Post RM, Rapport DJ, Russell JM, Sachs GM, Zajecka J (2000) Development and validationof a screening instrument for bipolar spectrum disorder: The Mood Disorder Questionnaire. Am J Psychiatry 157:1873-1875

19. Kaufman J, Birmaher B, Axelson D, Perepletchikova F, Brent D, Ryan N (2013) Schedule for Affective Disorders and Schizophrenia for School-Age Children-Present and Lifetime Version (K-SADS-PL 2013, DSM-5). Western Psychiatric Institute and Yale University

20. Moussa S, Emadeldin M, Amer D, Awad MI, Ghanem M, Amin W, Zaki HS, Adel M (2011) Arabic version of Kiddie-Schedule for Affective Disorders and Schizophrenia - Present and Lifetime Version (K-SADS-PL). Unpublished manuscript. Cairo University, Cairo

21. Sparks GM, Axelson DA, Yu H, Ha W, Ballester J, Diler RS (2014) Disruptive mood dysregulation disorder and chronic irritability in youth at familial risk for bipolar disorder. J Am Acad Child Adolesc Psychiatry 53:408-416

22. DSM 5 (2013) American Psychiatric Association: Diagnostic and Statistical Manual of Mental Disorders, 5th Edition. Arlington, VA, American Psychiatric Association, p. 155-160

\section{Publisher's Note}

Springer Nature remains neutral with regard to jurisdictional claims in published maps and institutional affiliations.

\section{Submit your manuscript to a SpringerOpen ${ }^{\odot}$ journal and benefit from:}

- Convenient online submission

- Rigorous peer review

- Open access: articles freely available online

- High visibility within the field

- Retaining the copyright to your article

Submit your next manuscript at $\boldsymbol{\nabla}$ springeropen.com 